\title{
Defining a pelagic typology of the eastern English Channel
}

\author{
Juliette Delavenne*, Paul Marchal, Sandrine Vaz
}

Institute (IFREMER), Laboratoire Ressources Halieutiques, 150 quai Gambetta, BP699, 62321 Boulogne-surMer, France

*: Corresponding author : Juliette Delavenne, Tel.: +33 321995061 ;

email address : Juliette.delavenne@ifremer.fr

\begin{abstract}
:
Classifying marine habitats is a growing research field and is of increasing interest to spatial planners and managers. Most studies have predominantly focused on the seabed to determine benthic habitat types, and only limited attention has been paid to the water column. Classification projects aim at identifying candidate management units for the application of various regional or national regulations such as the European Water Framework Directive. Here, we propose a seasonal classification of the water column in the eastern English Channel, which we validated with biological data. For the three tested compartments, phytoplankton, zooplankton and pelagic fishes, the validation results were satisfactory, with recall values (i.e. percentage of observations correctly assigned in a given water type) ranging from 0.5 to 1 . This validation was a crucial step to verify that the proposed typology was ecologically relevant and to use it as a biodiversity surrogate in management and conservation plans. Because management plans are generally set on an annual rather than a seasonal basis, we also produced a "multi-seasonal" typology encompassing seasonal variability, which can be used as an appropriate all year round description of the water column attributes in the eastern English Channel. The "multi-seasonal" typology reflected the relative stability of the French waters and the central part of the eastern English Channel and the strongest variability of the English coastal waters and the Dover strait.
\end{abstract}

\section{Highlights}

Seasonal pelagic typologies of the eastern English Channel were defined. The ecological relevance of the winter and autumnal typologies was assessed to validate the approach. $A$ "multiseasonal" typology encompassing seasonal variability was produced.

Keywords: Eastern English Channel ; Pelagic typology ; Clustering analysis ; Seasonality 


\section{Introduction}

There has been in recent years an increasing demand, from marine policy-makers and managers, to develop knowledge about the distribution and habitat of marine organisms and thereby improve the scientific basis to Ecosystem-Based Management at international (International Council for the Exploration of the Sea, ICES or OSPAR for OSIoPARis convention initiatives), regional (Marine Strategy Framework Directive) and national levels (Coggan and Diesing, 2011; Costello, 2009). Thus, habitat typologies, which are now commonly used as biodiversity surrogates in Ecosystem-Based Management or conservation planning (Moilanen et al., 2009), have increasingly been investigated in the last decade in habitat mapping studies.

Habitat classification approach is driven by the need to capture similarity and changes in biodiversity (Costello, 2009). There is no unique, widely accepted, definition of habitat. Depending on the purpose and the scale of the study, a habitat can be defined by different features such as geography, physical parameters or species composition (Costello, 2009). A habitat may be described by a set of abiotic features and it is not necessary to refer to the traits of an organism when describing habitat (Kearney, 2006). In this study, habitats are defined according to the EUNIS definition (European Nature Information System): "a habitat is a place characterized primarily by its physical features and secondarily by the species of plants or animals that live there" (Davies et al., 2004). Although most of the European continental shelf seabed has already been categorized (Cameron and Askew, 2011; Connor et al., 2006), there are only few examples of classification of the water column above the seabed. However, the pelagic realm represents $99 \%$ of the biosphere volume (Game et al., 2009) and represents a distinct, vastly unexplored part of the EUNIS habitat classification.

The present study took place in the eastern English Channel (EEC), which is a very important area from an economic and ecological point of view. It supports spawning grounds and nurseries for various fish including valuable commercial species (Carpentier et al., 2009; Loots et al., 2010), and it is also a migratory route for fish, birds, and marine mammals. The EEC is also a biogeographical transition zone between the warm temperate Atlantic oceanic system and the boreal North Sea, and it encompasses a wider range of ecological conditions than many other European seas (Carpentier et al., 2009; Dauvin, 2008). In addition, the EEC is an intensively used area, which provides substantial economic return for fisheries, maritime traffic, aggregate extractions and other economic sectors (Buléon and ShurmerSmith, 2008).

Whereas a seabed typology has already been defined for the EEC based on physical data (Coggan and Diesing, 2011), or benthic communities (MESH, 2008), few attempts have been made to describe its water column (Connor et al., 2006). However, the pelagic realm is of primary importance for many organisms living in the EEC. This applies of course to pelagic, but also to those bentho-demersal organisms that are influenced by both the seabed and the water column, and even to numerous benthic species, which are subject to a pelagic phase during their life cycle. Various studies investigating habitat models for different species, including benthic invertebrates, fishes and cephalopods (Carpentier et al., 2009; Martin et al., 2010; Vaz et al., 2008) showed that proxy of the water masses such as temperature, salinity or turbidity determined to a large extent the distribution of those species habitats. These results suggest that the characteristics of the water column should also be taken into account to develop management and conservation plans that would comprehensively protect the EEC's biodiversity.

In this study, seasonal water column typologies of the EEC were developed to take into account the most important part of the temporal variability of the water column. The seasonal typologies obtained in the present work were tested against various biological datasets from 
autumnal and winter survey data available for these two seasons. This was done to verify the extent to which the water masses so defined could discriminate between the different ecological communities. Finally, a "multi-seasonal" pelagic typology was produced that integrated all four season's characteristics and encompassed seasonality into a single, all year round summary typology which could be used for management and spatial planning purposes

\section{Materials and methods}

\subsection{The study area}

The eastern English Channel (EEC) (figure 1) is a shallow epicontinental sea located in the temperate Northeast Atlantic, covering $\sim 35000 \mathrm{~km}^{2}$ and separating the south coast of the UK from the north coast of France. The EEC is influenced by the Atlantic Ocean to the west and is connected to the North Sea through the Dover Strait. Hence, oceanic waters cross the EEC towards the North Sea under a dominant westerly winds regime. In terms of hydrodynamic conditions, the EEC is characterized by its strong tidal currents and the seabed shear stress resulting from tidal currents on the bottom may be relatively high, especially in narrow areas. These hydrodynamic conditions lead to a sediment gradient, from gravels and pebbles in areas with strong currents to fine sediments in bays and estuaries (Carpentier et al., 2009). Due to the low bathymetry and the strong currents, the water column is well mixed. The shallow inshore areas show large seasonal temperature variations compared to the deeper offshore waters, which remain more stable. This leads to an inversion of the temperature gradient with coastal waters colder than offshore waters in winter and conversely in summer. This pattern is also largely influenced by large freshwaters inputs along the French coast with a resulting reduced salinity (Carpentier et al., 2009).

\subsection{The descriptors of the water column}

To produce a pelagic typology of the EEC, different environmental data layers have been gathered from various sources. The choice of these data was based on their known contribution to the structuration of the different biological communities of the study area, and also on their availability over the whole EEC area. Some data were in-situ observations, while others were model-derived.

\subsubsection{Persistent parameters: depth, seabed shear stress and annual temperature contrast.}

Depth combined both bathymetry and hydrodynamic modeled mean sea level, to illustrate the average water column thickness at mid-tide for an average tide coefficient. Bathymetric data were derived from SHOM (Service Hydrographique et Océanographique de la Marine) hydrographic charts and the mean sea level was estimated using a hydrodynamic model (Carpentier et al., 2009).

Because the EEC is a megatidal area, the strength of tidal currents is an important structuring feature for the water column, and this has been estimated by the seabed shear stress which was estimated using a 2-D hydrodynamic model originally developed for the Irish Sea but extended to cover the Northwest European shelf (Alridge and Davies, 1993). Both depth and bedstress were constant physical parameters across seasons.

The difference of temperature between the maximum (in August) and the minimum (in February) was added as a third constant parameter because this yearly temperature 
variation may highlight the "coastal flow" structure which is a particularly structuring feature of this area (Brylinsky and Laguadeuc, 1990; Koubbi et al., 2006). It was calculated with monthly satellite imagery data averaged from 1986 to 2006.

2.2.2. Seasonal parameters: surface temperature, bottom salinity, light penetration and current speed.

Four seasonal parameters were used in addition to the three constant parameters detailed above: the surface temperature and an indice of photosynthetically available radiation, which were both derived from satellite imagery data, and bottom salinity and surface current speeds, which are interpolated in situ observations and model outputs respectively.

The sea surface temperature (SST) was calculated using the infra-red channels of the AVHRR (Advanced Very High Resolution Radiometer) sensor on-board NOAA (National Oceanic and Atmospheric Administration) satellites platforms using the calculation algorithm described in Walton et al. (1998).

The Photosynthetically Available Radiation (PAR) domain ranges from 400 to700 $\mathrm{nm}$. Its coefficient of attenuation, the $\mathrm{K}_{\mathrm{PAR}}$, is correlated to the suspended particulate matter data and Chlorophyll $a$ and can be considered as a water turbidity indicator. Both SST and K KAR were available as monthly averages, over the last 21 years (Carpentier et al., 2009; Gohin et al., 2005).

The bottom salinity came from the freely available ICES oceanographic database and was available as monthly averages between 1971 and 2000 (Berx and Hughes, 2009).

The surface current speed data have been extracted from the ECOSMO model (Schrum et al., 2006), and these were also available as monthly averages.

Seasonal means were calculated for the monthly surface temperature, salinity, $\mathrm{K}_{\mathrm{PAR}}$ and current speed parameters. The seasons were chosen to coincide with the water column classification work developed in the UKseaMap project 2006 (Connor et al., 2006) : spring (March, April, May), summer (June, July, August), autumn (September, October, November) and winter (December, January, February). All persistent and seasonal variables were resampled on a regular grid of $10 \mathrm{~km}$ representing 610 grid cells.

\subsection{Classification methodology}

A Gower dissimilarity coefficient was calculated (Gower, 1971; Legendre and Legendre, 1998) on standardized data and a Hierarchical Agglomerative Clustering (HAC) method was then applied to the resulting dissimilarity matrix. The group average method (or unweighted pair-group method) was used; this technique accounts for group structure and it is reasonably space-conserving. In other words, the probability to be associated to a group is not determined by its size. Four seasonal classifications were produced using the seven parameters described above.

In addition, an integrated typology was produced to reflect the multi-seasonal variability performing an HAC on 19 parameters: the three persistent parameters, and each seasonal value of the four other descriptors.

The classification cut level was obtained by combining two criteria. The optimal number of groups to retain was established by using the Calinsky criterion (Calinsky and Harabasz, 1974; Guidi et al., 2009; Milligan and Cooper, 1985; Smith et al., 2008) which compares the 
sum of squares of the partition between and within groups. This criterion was applied to all resulting dendrograms. Then, in order to prevent large numbers of undersized groups with small spatial extent, some clusters were regrouped to the upper cut level to have at least $1 \%$ of the observations into each group.

\subsection{Interpolation of the classification outputs:}

The continuous maps of the pelagic typologies were obtained using indicator kriging of each $10 \mathrm{~km}$ resolution classification outputs on a $1 \mathrm{~km}^{2}$ resolution. This interpolation technique is adapted to nominal variables (Webster and Oliver, 2001) and resulted into an interpolated map of occurrence probability of each class at any given location. The maps of the seven classes were then combined selecting at each location the class with the highest probability of occurrence, each class corresponding to a water mass.

\subsection{Evaluation of the classification outputs using Principal Component Analysis}

In order to verify the representativeness and robustness of the resulting clusters, the classification outputs (10 km resolution typologies) were projected in a Principal Component Analysis (PCA) to verify that each cluster could be clearly distinguished from each other in a reduced ordinated space.

\subsection{Ecological validation of the seasonal typologies}

In order to verify that each seasonal typology had an ecological relevance, the seven water masses were tested to verify that they were truly different in term of their composition in pelagic fishes or planktonic taxa. Unfortunately, due to limited data availability, only the winter and the autumnal typologies were investigated in this way. Biological datasets used for this validation originated from two scientific surveys: the Channel Ground Fish Survey (CGFS) and the International Bottom Trawl Survey (IBTS). The CGFS covers exclusively the EEC in October since 1988. The IBTS normally occurs in January in the North Sea, but its coverage was extended to the EEC since 2008. The autumnal typology was tested against the pelagic fish and cephalopods abundances recorded in the CGFS trawls between 1988 and 2010 (Table 1). Because of the large inter-annual variability in this data set, species abundance data were averaged over time on a $0.1^{\circ}$ regular grid. The winter typology was tested against three biological compartments: pelagic fish and cephalopods (from 2008 to 2011), zooplankton (2008) and phytoplankton (from 2008 to 2010). Since the typology definition was $10 \mathrm{~km}$, the biological stations located less than five kilometers away from the boundary between two water masses were removed from the analyses to avoid edge effect. First, the homoscedasticity hypothesis was tested with the Marti Anderson's method (Anderson et al 2006), which is a multivariate equivalent of Leven's test or homogeneity of variances. In order to improve the variance homogeneity, all abundance data were logtransformed. Then, an analysis of similarities (ANOSIM) was realized to determine if the biological compositions of the different water masses were statistically different $(p<0.001)$. This analysis consisted in looking at the ranked dissimilarities between and within groups (Clarke, 1993). Finally, linear discriminant analyses were conducted to determine the extent to which the water masses were able to reveal differences in biological communities, i.e. if they were good predictors of the biological communities' structure. The discriminant analysis produced contingency tables representing the percentage of correct group allocations, as predicted by the analysis. The significance of the discriminant analysis results was tested by comparing intra-group and total variances with a Bartlett test (Bartlett, 1937). 
All the analyses were performed using the R statistical software (http://www.R-project.org/) with cluster and vegan packages.

\section{Results}

\subsection{The seasonal typologies}

Four seasonal typologies were obtained from each classification of the seasonal parameters and these were mapped in figure 2. The environmental characteristics of the different water masses were described in table 2 and some were illustrated in figure 3 . Each seasonal classification resulted into seven water masses. For the integrated typology representing the multi-seasonal variability, the classification resulted in a higher number of groups (Figure 4). The Calinski criterion was best for 16 groups and this number was subsequently tailored down to 13 water masses, so to have more than $1 \%$ of the observations in each group.

In the four seasonal typologies, some water masses appeared to be stable and exhibited a certain spatial persistence although they were not identical from season to season (Figure 2). The types 3sp, 3su, 3a and 3w looked similar by their locations even if their mean values for environmental parameters such as temperature or salinity were different throughout the year. The deepest water masses of the area always had the strongest bedstress and surface current (Table 2). We can observe that the types 2sp, 2su, 2a and 2w (French coasts) and the types $4 \mathrm{sp}$, 4su, $4 \mathrm{a}$ and $4 \mathrm{w}$ (central Channel) were also spatially persistent throughout the year. By contrast, the water masses associated to the English coasts and the Dover Strait appeared more season-dependent. This was reflected in the multi-seasonal typology (Figure 4), where the stable French coast and central Channel water masses were still present, while the English coasts, Dover Strait and estuaries were composed of more water types and were more scattered.

The PCA showed that the 7 water masses could be clearly discriminated on the first two axes for each seasonal typology (Figure 5). These results also confirmed that it was not necessary to proceed to an ordination of the data, before the realization of a classification. Moreover, more than $50 \%$ of the variance was explained on the first axis indicating that a strong environmental gradient strongly structured the data. The water types $1 \mathrm{a}, 1 \mathrm{w}, 1 \mathrm{sp}$ and 1su were always well separated from the 6 other water types and were characterized by high $\mathrm{K}_{\mathrm{PAR}}$ values. For the four seasons, a gradient from the types 1, 2, 4 and 3 was clearly noticeable along the first axis following a gradient of decreasing temperature variability, and increasing depth, current speed and bedstress. The transition patterns to water masses 5,6 and 7 were more variable and season specific. The figure 3 illustrated the seasonal variation for four of the seven variables used. Depth, bedstress, SST and salinity were chosen because their contributions to the first two axes of the PCA were the most important. Only the types 1 (sp, su, a, w), 2 (sp, su, a, w), 3 (sp, su, a, w) and 4 (sp, su, a, w) were presented because of their relative spatial stability over time, which was well illustrated by the depth and bedstress plots showing little variations over the four seasons.

\subsection{The biological validation}

ANOSIM analyses were conducted for each available biological datasets separately. A significant result meant that the tested biological compositions were different for each defined water mass $(p<0.001)$. For the pelagic fishes against the autumnal typology, the ANOSIM statistic ( $R$ value) was equal to 0.28 , and significant. For the winter typology, the ANOSIM 
results were significant for each of the three biological datasets with $R$ equal to 0.27 for the phytoplankton, 0.20 for the zooplankton and 0.26 for the pelagic fishes. This was further confirmed and detailed for each water mass with the discriminant analyses results (Table 3 ). For each dataset analysis, a significant Bartlett test indicated that the biological communities were different across water types. The contingency tables (Table 3 ) showed the quality of the discrimination of each separate water mass. High recall values were observed for the phytoplankton and zooplankton communities, which were found to be very coherent with the proposed pelagic typologies. The recall value was equal to 1 for all phytoplankton data classes, and exceeded 0.5 for the zooplankton. Moreover, the few misclassified observations were always placed in adjacent water types. Concerning the pelagic fish the recall value ranged from 0.75 to 0.94 . The weakest score corresponded to the water mass $3 \mathrm{w}$ containing only 4 observations, out of which 1 was placed in the adjacent type $4 \mathrm{w}$. For the autumnal typology, the available dataset was much larger and variable than those available for the winter validation. Still, the recall values were high, ranging from 0.65 to 0.95 . Globally the discriminant analyses results had high recall scores and validated the proposed pelagic typologies in winter and autumn.

\section{Discussion}

A pelagic typology of the entire French coast was produced by Gaillard-Rocher (2012) to answer the need of the Marine Strategy Framework Directive implementation in the French waters. This typology used the same parameters for the English Channel and the Bay of Biscay. Although this first attempt offered a good methodological coherence at the national level, it only resulted in few water types in the EEC as many of the descriptors used focused on water vertical stratification and the strong tidal features of this particular area were poorly described. The study presented here went a step further, with more detailed and appropriate parameters at the scale of the eastern English Channel, and with a biological validation of the seasonal typologies. Constructed from both modeled and field data, the proposed seasonal and multi-seasonal typologies were believed to be an appropriate representation of the water masses evolution along a year cycle at the scale of the eastern English Channel. Since the EEC water column is well mixed all year round and fronts are not persistent structures at the seasonal scale, the typologies were produced in two dimensions.

The seasonal and multi-seasonal typologies reflected the major hydrological characteristics of the eastern English Channel. Some water types appeared to be very stable during the year, certainly due to the influence of strong structuring physical parameters such as tide driven bedstress or depth, which were constant throughout the year. The central EEC water type (4sp, 4su, 4a and 4w) was the deepest and looked stable over the year even though its extent could vary. Similarly, the location and extent of water type 3 (3sp, 3su, 3a and 3w), which was the one subject to the strongest currents, varied little over seasons. This was also illustrated by the low variation in depth, bedstress and SST values in these two groups over the four seasons. These two offshore water masses also had a less important SST intraannual variation; they were more directly influenced by oceanic waters from the western English Channel and the Celtic Sea than by coastal and terrestrial factors, and in consequence had more stable oceanic parameters. Coastal water masses seemed more variable, certainly due to the large influence of season-dependent parameters such as temperature or turbidity. For example, the water mass 1 represented estuarine waters but although this type contained the Thames and the Seine estuaries all year round, it also contained the Somme estuary and its surrounding area during summer. In summer, the characteristics of this area were more similar to that of the two other estuaries than in the other seasons with higher surface temperature and $\mathrm{K}_{\mathrm{PAR}}$. But even if coastal water types were more variable, water masses along the English coasts and the Dover Strait were less stable than those along the French coast which was represented by the water mass 2 in the 
four seasons. This was also highlighted by the multi-seasonal map, which exhibited smaller areas close to the English coast and the Dover strait reflecting the stronger variability of these areas along the years.

Accounting for the temporal variability of the water masses for management purpose or conservation areas design is not always feasible. Therefore, besides the seasonal typologies, it appeared important to produce this "multi-seasonal" typology, which would integrate the seasonal variability and may be used as an appropriate "all year round" typology of the water masses in the eastern English Channel.

The validation of the typologies with biological datasets is a crucial step to verify that the water masses defined may be used as pelagic biodiversity surrogates for management or conservation purposes (Grantham et al., 2011; Gregr et al., 2012; Snelder et al., 2005) and unfortunately this validation step is almost never carried out. In the study area, the UK SeaMap project (Connor et al., 2006) constituted a first attempt at defining a pelagic typology at the UK water scale and they validated their seasonal water types with phytoplankton data. However, their validation exercise was built on annual mean distribution data of only 5 plankton indicators, which limited the scope of their conclusions. In this study, the seasonal resolution of the biological datasets used for the validation was consistent with the produced typologies. The biological characterization showed that the different water types tested were significantly different from a biological point of view and were also able to discriminate between different biological communities in autumn and winter. Although these taxonomically rich communities are known to be patchy and very variable at much smaller spatial and temporal scales than the proposed study extent or seasons (Carpentier et al., 2009; Koubbi et al., 2006), the results of the discriminant analysis confirmed as expected that phytoplankton and zooplankton composition were very different depending on water masses and that the proposed typologies were relevant to these taxa.

Even though discrimination results had lower recall values for pelagic fishes than for the other taxa, the results showed that the proposed typologies were also reasonable predictors for the pelagic fish assemblages which was a comforting result considering the mobility and large distribution pattern of these organisms. It would have been useful to develop this biological characterization for spring and summer but no relevant data were available on these periods for the pelagic biological compartment at the scale of the entire EEC. Moreover, no relevant biological dataset was available all year round to enable the evaluation of the multi-seasonal typology. Finally, besides plankton and fish data, this study would be complete with a validation with large megavertebrates such as cetaceans or sharks.

Many statistical methods such as generalized dissimilarity models (GDM) exist to produce bioregionalization based both on environment and biological data (Koubbi et al., 2011). However, we wanted to have a "EUNIS-like" approach and for the description level required, EUNIS advises to produce typologies based on environmental data only. The integration of biological communities as a classification criterion might have refined the typologies but their description were not available for each season. Moreover, although a map of the fish communities was published by Vaz et al (2007), no such outputs exist for phytoplankton or zooplankton at the Channel scale because not enough data were available.

The proposed typologies were the first attempt to produce seasonal pelagic typologies at the scale of the eastern English Channel. Our results may inform managers responsible of the enforcement of the European Water or Marine Strategy Framework Directives, and support marine spatial planning in the eastern English Channel. In most of the conservation planning studies intending to design Marine Protected Areas (MPA) networks, benthic habitats are used as biodiversity surrogates but they may not be always representative of pelagic biodiversity (Game et al., 2009; Grantham et al., 2011). The produced pelagic typologies 
could be used to this purpose as a complementary biodiversity surrogate to take into account the global biological diversity in the area. However, it still has to be stressed that even though the produced typologies may be used as a preliminary pelagic biodiversity surrogate, further work needs to be done to include explicitly habitats with essential functions such as nurseries or spawning grounds in any management or conservation plan. Therefore, the present typologies may be representative of the pelagic biodiversity at the EEC scale but does not comprehensively reflect the whole functional diversity of the area.

\section{Achnowledgements}

We wish to acknowledge financial support from the INTERREG IV A France (Channel) England cross-border European cooperation program, co-financed by the European Regional Development Fund as part of the CHannel integrated Approach for marine Resource Management (CHARM) Phase 3 project. Juliette Delavenne received additional funding through a PhD studentship granted by the Syndicat Mixte Côte d'Opale (SMCO). We thank all our colleagues who collected the survey data and Martin Huret for useful discussions.

\section{Bibliography}

Alridge, J.N., Davies, A.M., 1993. A high resolution three dimensional hydrodynamic model of the eastern Irish Sea journal of physical oceanography 23.

Bartlett, M.S., 1937. Properties of sufficiency and statistical tests. Proceedings of the royal society of London series $160,268-282$.

Berx, B., Hughes, S.L., 2009. Climatology of surface and Near-bed temperature and salinity on the Noth-West European continental shelf for 1971-2000. Continental shelf research 29, 2286-2292.

Brylinsky, J.M., Laguadeuc, Y., 1990. L'interface eau côtière/eau du large dans le PAs de Calais (côte française): une zone frontale. Comptes-rendus de l'académie des sciences. Paris. 311, 535-540.

Buléon, P., Shurmer-Smith, L., 2008. Espace Manche, un monde en Europe - Channel spaces, a world within Europe, Caen.

Calinsky, R.B., Harabasz, J., 1974. A dendrite method for cluster analysis. Communications in statistics 3, 1-27.

Cameron, A., Askew, N., 2011. EUSeaMap - Preparatory action for development and assesment for a European broad-scale seabed habitat map final report, in: Cameron, A., Askew, N. (Eds.), p. 240.

Carpentier, A., Martin, C.S., Vaz, S., 2009. Channel Habitat Atlas for marine Resource Management, final report / Atlas des habitats des resources marines de la Manche orientale, rapport final (CHARM phase II). Interreg 3a Programme. IFREMER, Boulogne-sur-mer, France. 626pp. \& CD-rom.

Clarke, K.R., 1993. Non-parametric multivariate analyses of changes in commmunity structure. Australian journal of ecology 18, 117-143.

Coggan, R.A., Diesing, M., 2011. The seabed habitats of the central English Channel: A generation on from Holme and Cabioch, how do their interpretations match-up to modern mapping techniques. Continental Shelf Research 31, S132-S150.

Connor, D.W., Gilliand, P.M., Golding, N., Robinson, P., Todd, D., Verling, E., 2006. UKSeaMap: the mapping of seabed and water column features of UK seas. Joint Nature Conservation Committee, Peterborough. Available at: http://www.jncc.gov.uk/page-3918.

Costello, M.J., 2009. Distinguishing marine habitat classification concepts for ecological management. Marine Ecology Progress Series 397, 253-268. 
Dauvin, J.C., 2008. The main characteristics, problems, and prospects for Western European coastal seas. Marine Pollution Bulletin 57, 22-40.

Davies, C.E., Moss, D., O Hill, M., 2004. EUNIS habitat classification revised 2004. European environment agency, p. 307.

Gaillard-Rocher, I., Huret, M., Lazure, P., Vandermeirsch, F., Gatti, J., Gareau, P., Gohin, F., 2012. identification de "paysages hydrologiques" dans les eaux marines sous juridiction française (France métropolitaine). IFREMER.

Game, E.T., Grantham, H.S., Hobday, A.J., Pressey, R.L., Lombard, A.T., Beckley, L.E., Gjerde, K., Bustamante, R., Possingham, H.P., Richardson, A.J., 2009. Pelagic protected areas: the missing dimension in ocean conservation. Trends in Ecology \& Evolution 24, 360369.

Gohin, F., Loyer, S., Lunven, M., Labry, C., Froidefond, J.M., Delmas, D., Huret, M., Herbland, A., 2005. Satellite-derived parameters for biological modelling in coastal waters.: illustration over the eastern continental shel of the Bay of Biscay. Remote sensing of Environment 95, 29-46.

Gower, J.C., 1971. A General Coefficient of Similarity and Some of Its Properties. Biometrics 27, 857-871.

Grantham, H.S., Game, E.T., Lombard, A.T., Hobday, A.J., Richardson, A.J., Beckley, L.E., Pressey, R.L., Huggett, J.A., Coetzee, J.C., van der Lingen, C.D., Petersen, S.L., Merkle, D., Possingham, H.P., 2011. Accommodating Dynamic Oceanographic Processes and Pelagic Biodiversity in Marine Conservation Planning. PLoS ONE 6, e16552.

Gregr, E.J., Ahrens, A.L., Perry, R.I., 2012. Reconciling classifications of ecologically and biologically significant areas ni the world's oceans. Marine Policy 36, 716-726.

Guidi, L., Ibanez, F., Calcagno, V., Beaugrand, G., 2009. A new procedure to optimize the selection of grops in a classification tree: applications for ecological data. Ecological Modelling 220, 451-461.

Kearney, M., 2006. Habitat, environment and niche: what are we modelling? Oikos 115, 186191.

Koubbi, P., Loots, C., Cotonnec, G., Harlay, X., Grioche, A., Vaz, S., Martin, C.S., Walkey, M., Carpentier, A., 2006. Spatial patterns and GIS habitat modelling of Solea solea, Pleuronectes flesus and Limanda limanda fish larave in the eastern english Channel during the spring. Scientia Marina 70.

Koubbi, P., Moteki, M., Duhamel, G., Goarant, A., Hulley, P.-A., O'Driscoll, R., Ishimaru, T., Pruvost, P., Tavernier, E., Hosie, G., 2011. Ecoregionalization of myctophid fish in the Indian sector of the Southern Ocean: Results from generalized dissimilarity models. Deep Sea Research Part II: Topical Studies in Oceanography 58, 170-180.

Legendre, P., Legendre, L., 1998. Numerical Ecology. Elsevier, Amsterdam.

Loots, C., Vaz, S., Koubbi, P., Planque, B., Coppin, F., Verin, Y., 2010. Inter-annual variability of North Sea plaice spawning habitat. Journal of Sea Research 64, 427-435.

Martin, C.S., Vaz, S., Ellis, J.R., Coppin, F., Le Roy, D., Carpentier, A., 2010. Spatiotemporal patterns in demersal elasmobranchs from trawl surveys in the eastern English Channel (1988-2008). Marine Ecology Progress Series 417, 211-228.

$\mathrm{MESH}, 2008$. MESH. The Mesh Blue Book. A summary of achievements of the MESH project. 24 pp. Available at: http://www.searchmesh.net/PDF/Final\%20MESH\%20EXEC\%20SUM\%20v7.pdf.

Milligan, G.W., Cooper, M.C., 1985. A examination of procedures for determining the nulber of clusters in a data set. Psychometrika 50, 159-179.

Moilanen, A., Wilson, K.A., Possingham, H., 2009. Spatial conservation prioritization: quantitative methods and computational tools. Oxford University Press, Oxford.

Schrum, C., Alekseeva, I., St. John, M., 2006. Development of a coupled physical-biological ecosystem model ECOSMO. Part 1: Model description and validation for the North Sea Journal of Marine Systems 61, 79-99.

Smith, R.J., Easton, J., Nhancale, B.A., Armstrong, A.J., Culverwell, J., Dlamini, S.D., Goodman, P.S., Loffler, L., Matthews, W.S., Monadjem, A., Mulqueeny, C.M., Ngwenya, P., Ntumi, C.P., Soto, B., Leader-Williams, N., 2008. Designing a transfrontier conservation 
landscape for the Maputaland centre of endemism using biodiversity, economic and threat data. Biological Conservation 141, 2127-2138.

Snelder, T., Leathwick, J., Dey, K., Weatherhead, M., Fenwick, G., Francis, M., Gorman, R., Grieve, J., Hadfield, M., Hewitt, J.E., Hume, T., Richardson, K., Rowden, A., Uddstrom, M., Wild, M., Zeldis, J., 2005. The New Zealand Marine Environment Classification. Ministry for the environment.

Vaz, S., Carpentier, A., Coppin, F., 2007. Eastern English Channel fish assemblages: measuring the structuring effects of habitats on distinct sub-communities. Ices Journal of Marine Science 64, 271-287.

Vaz, S., Carpentier, A., Coppin, F., 2008. Modelling fish communities habitat in the eastern english Channel: Tentative prediction of habitat distribution change under different climatic variation scenarios, ICES conference, Halifax, Canada.

Walton, C.C., Pichel, W.G., Sapper, F.J., Andmay, D.A., 1998. The development of operationnal application of non linear algorithms for the measurement of sea surface temperatures with NOAA polarorbiting environmental satellites. journal of geophysical research 103, 27999-28102.

Webster, R., Oliver, M.A., 2001. Geostatistics for environment scientists. Wiley, Chichester.

\section{Tables}

Table1: Taxa used in the study, originating from the IBTS survey for the winter observations and from the CGFS survey for the autumn ones. Only the 10 more frequent taxa are cited for the zooplankton (35 taxa in total) and the phytoplankton (94 taxa in total). $\mathrm{N}$ is the number of observations.

\begin{tabular}{|c|c|c|c|}
\hline Pelagic fishes (autumn) & Pelagic fishes (Winter) & $\begin{array}{l}\text { Zooplankton } \\
\text { (winter) }\end{array}$ & $\begin{array}{l}\text { Phytoplankton } \\
\text { (winter) }\end{array}$ \\
\hline $\begin{array}{l}\text { Horse Mackerel } \\
\text { (Trachurus trachurus) }\end{array}$ & $\begin{array}{l}\text { Horse Mackerel } \\
\text { (Trachurus trachurus) }\end{array}$ & Appendicularia & Cryptophyceae spp. \\
\hline Sprat (Spratus spratus) & Sprat (Spratus spratus) & Brachyura & Nitzschialongissima \\
\hline $\begin{array}{l}\text { Herring (Clupea } \\
\text { harengus) }\end{array}$ & $\begin{array}{l}\text { Herring (Clupea } \\
\text { harengus) }\end{array}$ & Acartia & Gymnodinium spp. \\
\hline $\begin{array}{l}\text { Sardine (Sardina } \\
\text { pilchardus) }\end{array}$ & $\begin{array}{l}\text { Sardine (Sardina } \\
\text { pilchardus) }\end{array}$ & $\begin{array}{l}\text { Paracalanus } \\
\text { spp. }\end{array}$ & Paraliasulceta \\
\hline $\begin{array}{l}\text { Northern squid (Loligo } \\
\text { forbesi) }\end{array}$ & $\begin{array}{l}\text { Northern squid (Loligo } \\
\text { forbesi) }\end{array}$ & Pseudocalanus & Thalassiosina spp. \\
\hline $\begin{array}{l}\text { European squid (Loligo } \\
\text { vulgaris) }\end{array}$ & $\begin{array}{l}\text { European squid (Loligo } \\
\text { vulgaris) }\end{array}$ & Temora & Ciliophora spp. \\
\hline $\begin{array}{l}\text { Mackerel (Scomber } \\
\text { scombrus) }\end{array}$ & $\begin{array}{l}\text { Mackerel (Scomber } \\
\text { scombrus) }\end{array}$ & Calanoida & Nanoflagellés spp. \\
\hline $\begin{array}{l}\text { Black bream } \\
\text { (Spondyliosoma } \\
\text { cantharus) }\end{array}$ & $\begin{array}{l}\text { Black bream } \\
\text { (Spondyliosoma } \\
\text { cantharus) }\end{array}$ & Chaetognata & $\begin{array}{l}\text { Skelatoneam } \\
\text { costatum }\end{array}$ \\
\hline $\begin{array}{l}\text { Gilthead seabream } \\
\text { (Sparus aurata) }\end{array}$ & & Centropaeges & Pleurosigma spp. \\
\hline $\begin{array}{l}\text { Seabass (Dicentrarchus } \\
\text { labrax) }\end{array}$ & & Clupeidae & Mediophyceae spp. \\
\hline \multicolumn{4}{|l|}{$\begin{array}{l}\text { Anchovy (Engraulis } \\
\text { encrasicolus) }\end{array}$} \\
\hline $\mathrm{N}=138$ & $\mathrm{~N}=61$ & $\mathrm{~N}=18$ & $\mathrm{~N}=88$ \\
\hline
\end{tabular}


Table 2: Physical characteristics of each typology: mean and standard deviations (sd). a) spring typology, b) summer, c) autumn, d) winter and e) multi-seasonal typology.

a)

\begin{tabular}{|c|c|c|c|c|c|c|c|}
\hline & Depth & $\begin{array}{c}\text { Shear } \\
\text { bedstress }\end{array}$ & $\begin{array}{c}\text { SST } \\
\text { variation }\end{array}$ & SST & Salinity & KPAR & $\begin{array}{c}\text { Current } \\
\text { speed }\end{array}$ \\
\hline \multirow{2}{*}{$\mathbf{~ s p}$} & 10.26 & 1.03 & 11.7 & 8.99 & 34.6 & 1.651 & 0.071 \\
& $(4.89)$ & $(0.480)$ & $(0.376)$ & $(0.262)$ & $(0.114)$ & $(0.162)$ & $(0.034)$ \\
\hline \multirow{2}{*}{$\mathbf{2 ~ s p}$} & 24.28 & 0.843 & 11.2 & 9.18 & 34.3 & 0.419 & 0.071 \\
& $(6.78)$ & $(0.370)$ & $(0.459)$ & $(0.172)$ & $(0.082)$ & $(0.161)$ & $(0.021)$ \\
\hline \multirow{2}{*}{$\mathbf{3} \mathbf{s p}$} & 58.6 & 2.93 & 8.19 & 9.40 & 34.8 & 0.322 & 0.197 \\
& $(9.45)$ & $(0.190)$ & $(0.664)$ & $(0.145)$ & $(0.081)$ & $(0.041)$ & $(0.062)$ \\
\hline \multirow{2}{*}{$\mathbf{4} \mathbf{s p}$} & 44.2 & 1.38 & 9.15 & 9.15 & 34.5 & 0.272 & 0.111 \\
& $(7.21)$ & $(0.471)$ & $(0.681)$ & $(0.087)$ & $(0.124)$ & $(0.037)$ & $(0.018)$ \\
\hline \multirow{2}{*}{$\mathbf{5} \mathbf{s p}$} & 18.5 & 1.19 & 10.1 & 8.95 & 34.8 & 0.685 & 0.093 \\
& $(9.12)$ & $(0.606)$ & $(0.594)$ & $(0.134)$ & $(0.069)$ & $(0.125)$ & $(0.042)$ \\
\hline \multirow{2}{*}{$\mathbf{6} \mathbf{s p}$} & 35.6 & 2.75 & 9.93 & 8.94 & 34.7 & 0.660 & 0.143 \\
& $(9.10)$ & $(0.339)$ & $(0.811)$ & $(0.175)$ & $(0.139)$ & $(0.224)$ & $(0.039)$ \\
\hline \multirow{2}{*}{$\mathbf{7 ~ s p}$} & 27.3 & 0.950 & 10.6 & 8.74 & 34.6 & 0.534 & 0.116 \\
& $(9.29)$ & $(0.481)$ & $(0.791)$ & $(0.138)$ & $(0.088)$ & $(0.255)$ & $(0.035)$ \\
\hline
\end{tabular}

b)

\begin{tabular}{|c|c|c|c|c|c|c|c|}
\hline & Depth & $\begin{array}{c}\text { Shear } \\
\text { bedstress }\end{array}$ & $\begin{array}{c}\text { SST } \\
\text { variation }\end{array}$ & SST & Salinity & KPAR & $\begin{array}{c}\text { Current } \\
\text { speed }\end{array}$ \\
\hline \multirow{2}{*}{$\mathbf{1}$ su } & 13.4 & 0.787 & 11.7 & 16.7 & 34.6 & 0.844 & 0.048 \\
& $(5.97)$ & $(0.454)$ & $(0.290)$ & $(0.278)$ & $(0.033)$ & $(0.292)$ & $(0.023)$ \\
\hline \multirow{2}{*}{$\mathbf{2}$ su } & 27.8 & 10.8 & 11.0 & 16.2 & 34.6 & 0.304 & 0.074 \\
& $(6.66)$ & $(0.354)$ & $(0.503)$ & $(0.303)$ & $(0.052)$ & $(0.097)$ & $(0.019)$ \\
\hline \multirow{2}{*}{$\mathbf{3} \mathbf{~ s u}$} & 60.4 & 2.94 & 7.98 & 14.9 & 34.9 & 0.199 & 0.186 \\
& $(8.11)$ & $(0.145)$ & $(0.398)$ & $(0.201)$ & $(0.021)$ & $(0.017)$ & $(0.069)$ \\
\hline \multirow{2}{*}{$\mathbf{4} \mathbf{~ s u}$} & 41.4 & 1.23 & 9.17 & 15.3 & 34.8 & 0.208 & 0.099 \\
& $(9.31)$ & $(0.507)$ & $(0.625)$ & $(0.275)$ & $(0.061)$ & $(0.046)$ & $(0.025)$ \\
\hline \multirow{2}{*}{$\mathbf{5} \mathbf{~ s u}$} & 14.0 & 1.01 & 10.4 & 16.1 & 34.9 & 0.427 & 0.099 \\
& $(7.18)$ & $(0.633)$ & $(0.325)$ & $(0.358)$ & $(0.049)$ & $(0.142)$ & $(0.048)$ \\
\hline \multirow{2}{*}{$\mathbf{6} \mathbf{~ s u}$} & 41.2 & 2.90 & 9.55 & 9.55 & 34.8 & 0.285 & 0.180 \\
& $(10.9)$ & $(0.186)$ & $(0.510)$ & $(0.510)$ & $(0.054)$ & $(0.058)$ & $(0.071)$ \\
\hline \multirow{2}{*}{$\mathbf{7} \mathbf{~ s p}$} & 31.0 & 2.56 & 10.6 & 10.6 & 34.0 & 0.375 & 0.177 \\
& $(8.44)$ & $(0.395)$ & $(0.514)$ & $(0.514)$ & $(0.040)$ & $(0.127)$ & $(0.029)$ \\
\hline
\end{tabular}


c)

\begin{tabular}{|c|c|c|c|c|c|c|c|}
\hline & Depth & $\begin{array}{c}\text { Shear } \\
\text { bedstress }\end{array}$ & $\begin{array}{c}\text { SST } \\
\text { variation }\end{array}$ & SST & Salinity & KPAR & $\begin{array}{c}\text { Current } \\
\text { speed }\end{array}$ \\
\hline $1 \mathbf{a}$ & $\begin{array}{c}12.3 \\
(6.95)\end{array}$ & $\begin{array}{c}0.997 \\
(0.451)\end{array}$ & $\begin{array}{c}11.7 \\
(0.354)\end{array}$ & $\begin{array}{c}14.7 \\
(0.357)\end{array}$ & $\begin{array}{c}34.8 \\
(0.136)\end{array}$ & $\begin{array}{c}1.60 \\
(0.285)\end{array}$ & $\begin{array}{c}0.083 \\
(0.038)\end{array}$ \\
\hline $2 \mathbf{a}$ & $\begin{array}{c}25.4 \\
(6.63)\end{array}$ & $\begin{array}{c}0.899 \\
(0.390)\end{array}$ & $\begin{array}{c}11.2 \\
(0.473)\end{array}$ & $\begin{array}{c}15.5 \\
(0.136)\end{array}$ & $\begin{array}{c}34.4 \\
(00.045)\end{array}$ & $\begin{array}{c}0.295 \\
(0.108)\end{array}$ & $\begin{array}{c}0.073 \\
(0.021)\end{array}$ \\
\hline $3 \mathbf{a}$ & $\begin{array}{c}53.1 \\
(13.8)\end{array}$ & $\begin{array}{c}2.94 \\
(0.170)\end{array}$ & $\begin{array}{c}8.54 \\
(0.870)\end{array}$ & $\begin{array}{c}15.6 \\
(0.137)\end{array}$ & $\begin{array}{c}34.5 \\
(0.036)\end{array}$ & $\begin{array}{c}0.324 \\
(0.111)\end{array}$ & $\begin{array}{c}0.200 \\
(0.064)\end{array}$ \\
\hline $4 a$ & $\begin{array}{c}45.2 \\
(7.18)\end{array}$ & $\begin{array}{c}1.45 \\
(0.472)\end{array}$ & $\begin{array}{c}9.02 \\
(0.682)\end{array}$ & $\begin{array}{c}15.6 \\
(0.086) \\
\end{array}$ & $\begin{array}{c}34.5 \\
(0.048)\end{array}$ & $\begin{array}{c}0.221 \\
(0.034)\end{array}$ & $\begin{array}{c}0.115 \\
(0.016) \\
\end{array}$ \\
\hline $5 \mathbf{a}$ & $\begin{array}{c}17.4 \\
(7.53)\end{array}$ & $\begin{array}{c}1.59 \\
(0.486)\end{array}$ & $\begin{array}{c}10.5 \\
(0.349)\end{array}$ & $\begin{array}{c}15.3 \\
(0.084)\end{array}$ & $\begin{array}{c}34.5 \\
(0.028)\end{array}$ & $\begin{array}{c}0.621 \\
(0.161)\end{array}$ & $\begin{array}{c}0.144 \\
(0.051)\end{array}$ \\
\hline $6 \mathbf{a}$ & $\begin{array}{c}24.7 \\
(11.4)\end{array}$ & $\begin{array}{c}0.674 \\
(0.309)\end{array}$ & $\begin{array}{c}10.1 \\
(0.679)\end{array}$ & $\begin{array}{c}15.4 \\
(0.102)\end{array}$ & $\begin{array}{c}34.6 \\
(0.075)\end{array}$ & $\begin{array}{c}0.445 \\
(0.180)\end{array}$ & $\begin{array}{c}0.121 \\
(0.047)\end{array}$ \\
\hline $7 \mathbf{a}$ & $\begin{array}{c}30.1 \\
(9.96)\end{array}$ & $\begin{array}{c}1.87 \\
(0.700)\end{array}$ & $\begin{array}{c}10.9 \\
(0.660)\end{array}$ & $\begin{array}{c}15.3 \\
(0.123)\end{array}$ & $\begin{array}{c}34.8 \\
(0.012)\end{array}$ & $\begin{array}{c}0.512 \\
(0.184)\end{array}$ & $\begin{array}{c}0.125 \\
(0.044)\end{array}$ \\
\hline
\end{tabular}

d)

\begin{tabular}{|c|c|c|c|c|c|c|c|}
\hline & Depth & $\begin{array}{c}\text { Shear } \\
\text { bedstress }\end{array}$ & $\begin{array}{c}\text { SST } \\
\text { variation }\end{array}$ & SST & Salinity & KPAR & $\begin{array}{c}\text { Current } \\
\text { speed }\end{array}$ \\
\hline \multirow{2}{*}{$\mathbf{1 w}$} & 11.3 & 0.977 & 11.7 & 7.53 & 34.6 & 2.46 & 0.097 \\
& $(5.96)$ & $(0.480)$ & $(0.479)$ & $(0.474)$ & $(0.088)$ & $(0.343)$ & $(0.047)$ \\
\hline \multirow{2}{*}{$\mathbf{2} \mathbf{w}$} & 24.9 & 0.864 & 11.2 & 8.27 & 34.2 & 0.396 & 0.085 \\
& $(7.04)$ & $(0.417)$ & $(0.458)$ & $(0.237)$ & $(0.112)$ & $(0.220)$ & $(0.027)$ \\
\hline \multirow{2}{*}{$\mathbf{3 w}$} & 57.1 & 2.95 & 8.30 & 9.89 & 34.7 & 0.336 & 0.214 \\
& $(10.5)$ & $(0.135)$ & $(0.698)$ & $(0.328)$ & $(0.076)$ & $(0.122)$ & $(0.058)$ \\
\hline \multirow{2}{*}{$\mathbf{4 w}$} & 45.5 & 1.42 & 8.93 & 9.52 & 34.4 & 0.279 & 0.131 \\
& $(6.7)$ & $(0.452)$ & $(0.554)$ & $(0.301)$ & $(0.104)$ & $(0.096)$ & $(0.015)$ \\
\hline \multirow{2}{*}{$\mathbf{5 w}$} & 34.5 & 2.69 & 10.2 & 8.84 & 34.6 & 0.838 & 0.179 \\
& $(6.40)$ & $(0.424)$ & $(0.450)$ & $(0.268)$ & $(0.104)$ & $(0.360)$ & $(0.046)$ \\
\hline \multirow{2}{*}{$\mathbf{6 w}$} & 26.2 & 0.998 & 10.2 & 8.83 & 34.5 & 0.674 & 0.129 \\
& $(10.5)$ & $(0.497)$ & $(0.526)$ & $(0.259)$ & $(0.150)$ & $(0.367)$ & $(0.049)$ \\
\hline \multirow{2}{*}{$\mathbf{7 w}$} & 20.1 & 1.54 & 11.6 & 7.87 & 34.7 & 0.679 & 0.109 \\
& $(5.66)$ & $(0.529)$ & $(0.371)$ & $(0.268)$ & $(0.058)$ & $(0.337)$ & $(0.027)$ \\
\hline
\end{tabular}


e)

\begin{tabular}{|c|l|l|l|l|l|l|l|}
\hline & Depth & $\begin{array}{c}\text { Shear } \\
\text { bedstress }\end{array}$ & $\begin{array}{c}\text { SST } \\
\text { variation }\end{array}$ & \multicolumn{1}{|c|}{ SST } & Salinity & KPAR & $\begin{array}{l}\text { Current } \\
\text { speed }\end{array}$ \\
\hline \multirow{2}{*}{$\mathbf{1}$} & 42.7 & 1.29 & 8.99 & 12.3 & 347 & 0.411 & 0.080 \\
& $(14.8)$ & $(0.576)$ & $(0.386)$ & $(0.154)$ & $(0.042)$ & $(0.122)$ & $(0.011)$ \\
\hline \multirow{2}{*}{$\mathbf{2}$} & 8.47 & 0.874 & 11.9 & 11.9 & 34.6 & 1.75 & 0.050 \\
& $(3.56)$ & $(0.378)$ & $(0.121)$ & $(0.280)$ & $(0.106)$ & $(0.222)$ & $(0.008)$ \\
\hline \multirow{2}{*}{$\mathbf{3}$} & 30.5 & 10.4 & 10.7 & 12.4 & 34.4 & 0.278 & 0.088 \\
& $(5.78)$ & $(0.361)$ & $(0.586)$ & $(0.234)$ & $(0.069)$ & $(0.079)$ & $(0.021)$ \\
\hline \multirow{2}{*}{$\mathbf{4}$} & 15.5 & 0.538 & 11.8 & 12.4 & 34.3 & 0.579 & 0.047 \\
& $(4.17)$ & $(0.228)$ & $(0.143)$ & $(0.150)$ & $(0.068)$ & $(0.216)$ & $(0.010)$ \\
\hline \multirow{2}{*}{$\mathbf{5}$} & 47.7 & 1.89 & 8.75 & 12.4 & 34.6 & 0.248 & 0.132 \\
& $(7.56)$ & $(0.763)$ & $(0.614)$ & $(0.202)$ & $(0.078)$ & $(0.050)$ & $(0.031)$ \\
\hline \multirow{2}{*}{$\mathbf{6}$} & 17.4 & 1.63 & 10.4 & 12.3 & 34.7 & 0.731 & 0.079 \\
& $(9.93)$ & $(0.984)$ & $(0.470)$ & $(0.206)$ & $(0.029)$ & $(0.128)$ & $(0.024)$ \\
\hline \multirow{2}{*}{$\mathbf{7}$} & 61.7 & 3.00 & 8.03 & 12.5 & 34.7 & 0.269 & 0.245 \\
& $(10.6)$ & $(2.31)$ & $(0.597)$ & $(0.195)$ & $(0.035)$ & $(0.034)$ & $(0.045)$ \\
\hline \multirow{2}{*}{$\mathbf{8}$} & 27.7 & 2.31 & 9.74 & 12.3 & 34.7 & 0.590 & 0.175 \\
& $(9.94)$ & $(0.844)$ & $(0.645)$ & $(0.221)$ & $(0.010)$ & $(0.126)$ & $(0.015)$ \\
\hline \multirow{2}{*}{$\mathbf{9}$} & 16.9 & 1.17 & 11.5 & 11.9 & 34.7 & 1.53 & 0.110 \\
& $(7.49)$ & $(0.492)$ & $(0.404)$ & $(0.188)$ & $(0.019)$ & $(0.319)$ & $(0.026)$ \\
\hline \multirow{2}{*}{$\mathbf{1 0}$} & 31.2 & 0.617 & 10.1 & 12.2 & 34.5 & 0.366 & 0.150 \\
& $(7.44)$ & $(0.236)$ & $(0.672)$ & $(0.222)$ & $(0.054)$ & $(0.115)$ & $(0.029)$ \\
\hline \multirow{2}{*}{$\mathbf{1 1}$} & 14.9 & 0.478 & 10.2 & 12.1 & 34.6 & 0.885 & 0.131 \\
& $(7.13)$ & $(0.271)$ & $(0.258)$ & $(0.116)$ & $(0.049)$ & $(0.251)$ & $(0.035)$ \\
\hline \multirow{2}{*}{$\mathbf{1 2}$} & 37.7 & 2.56 & 10.4 & 12.1 & 34.6 & 0.605 & 0.186 \\
& $(10.1)$ & $(0.447)$ & $(0.369)$ & $(0.143)$ & $(0.029)$ & $(0.278)$ & $(0.019)$ \\
\hline \multirow{2}{*}{$\mathbf{1 3}$} & 27.7 & 1.65 & 11.0 & 12.1 & 34.7 & 0.466 & 0.098 \\
& $(8.62)$ & $(0.612)$ & $(0.649)$ & $(0.260)$ & $(0.033)$ & $(0.011)$ & $(0.020)$ \\
\hline \multirow{2}{*}{} & & & & & & & \\
\hline
\end{tabular}


Table 3: Contingency tables from the discriminant analyses. The rows correspond to observed types based on the spatial location of observations, and the columns to the predicted water types based on the modeled relationships between the biological assemblages' structure and the proposed typology. The diagonal indicates the number of observations correctly allocated. The RECALL line shows the percentage of good reallocation (ratio between the points well reclassified compared to the total number of points in the class). Table $3 a$ represents the winter typology tested against the phytoplankton data, Table $3 \mathrm{~b}$ represents the winter typology tested against the zooplankton data, table $3 \mathrm{c}$ is the winter typology tested against the pelagic fish data and the table $3 \mathrm{~d}$ represents the autumnal typology tested against the pelagic fish data.

a)

\begin{tabular}{|l|l|l|l|l|l|l|}
\hline Predicted/Real & $\mathbf{2 w}$ & $\mathbf{3 w}$ & $\mathbf{4 w}$ & $\mathbf{5 w}$ & $\mathbf{6 w}$ & $\mathbf{7 w}$ \\
\hline $\mathbf{2 w}$ & $\mathbf{3 0}$ & 0 & 0 & 0 & 0 & 0 \\
\hline $\mathbf{3 w}$ & 0 & $\mathbf{6}$ & 0 & 0 & 0 & 0 \\
\hline $\mathbf{4 w}$ & 0 & 0 & $\mathbf{2 6}$ & 0 & 0 & 0 \\
\hline $\mathbf{5 w}$ & 0 & 0 & 0 & $\mathbf{1 7}$ & 0 & 0 \\
\hline $\mathbf{6 w}$ & 0 & 0 & 0 & 0 & $\mathbf{3}$ & 0 \\
\hline $\mathbf{7 w}$ & 0 & 0 & 0 & 0 & 0 & $\mathbf{6}$ \\
\hline RECALL & 1 & 1 & 1 & 1 & 1 & 1 \\
\hline
\end{tabular}

b)

\begin{tabular}{|l|l|l|l|l|l|}
\hline Predicted/Real & $\mathbf{2 w}$ & $\mathbf{4 w}$ & $\mathbf{5 w}$ & $\mathbf{6 w}$ & $\mathbf{7 w}$ \\
\hline $\mathbf{2 w}$ & $\mathbf{9}$ & 0 & 1 & 0 & 0 \\
\hline $\mathbf{4 w}$ & 1 & $\mathbf{3}$ & 0 & 0 & 0 \\
\hline $\mathbf{5 w}$ & 0 & 0 & $\mathbf{1}$ & 0 & 0 \\
\hline $\mathbf{6 w}$ & 0 & 0 & 0 & $\mathbf{1}$ & 0 \\
\hline $\mathbf{7 w}$ & 0 & 0 & 0 & 0 & $\mathbf{2}$ \\
\hline RECALL & 0.9 & 1 & 0.5 & 1 & 1 \\
\hline
\end{tabular}

c)

\begin{tabular}{|l|l|l|l|l|l|l|}
\hline Predicted/Real & $\mathbf{2 w}$ & $\mathbf{3 w}$ & $\mathbf{4 w}$ & $\mathbf{5 w}$ & $\mathbf{6 w}$ & $\mathbf{7 w}$ \\
\hline $\mathbf{2 w}$ & $\mathbf{1 6}$ & 0 & 0 & 0 & 0 & 0 \\
\hline $\mathbf{3 w}$ & 0 & $\mathbf{3}$ & 1 & 0 & 0 & 0 \\
\hline $\mathbf{4 w}$ & 2 & 1 & $\mathbf{1 6}$ & 1 & 1 & 0 \\
\hline $\mathbf{5 w}$ & 2 & 0 & 0 & $\mathbf{7}$ & 0 & 1 \\
\hline $\mathbf{6 w}$ & 0 & 0 & 0 & 0 & $\mathbf{4}$ & 0 \\
\hline 7w & 1 & 0 & 0 & 2 & 0 & $\mathbf{4}$ \\
\hline RECALL & 0.76 & 0.75 & 0.94 & 0.78 & 0.8 & 0.8 \\
\hline
\end{tabular}


d)

\begin{tabular}{|l|l|l|l|l|l|}
\hline Predicted/Real & $\mathbf{2 a}$ & $\mathbf{3 a}$ & $\mathbf{4 a}$ & $\mathbf{6 a}$ & $\mathbf{7 a}$ \\
\hline $\mathbf{2 a}$ & $\mathbf{2 8}$ & 0 & 3 & 4 & 0 \\
\hline $\mathbf{3 a}$ & 0 & $\mathbf{1 9}$ & 0 & 0 & 0 \\
\hline $\mathbf{4 a}$ & 7 & 1 & $\mathbf{4 2}$ & 1 & 0 \\
\hline $\mathbf{6 a}$ & 7 & 0 & 1 & $\mathbf{1 5}$ & 2 \\
\hline $\mathbf{7 a}$ & 1 & 0 & 0 & 0 & $\mathbf{7}$ \\
\hline RECALL & 0.65 & 0.95 & 0.91 & 0.75 & 0.78 \\
\hline
\end{tabular}

\section{Figures}

Figure 1: Study area

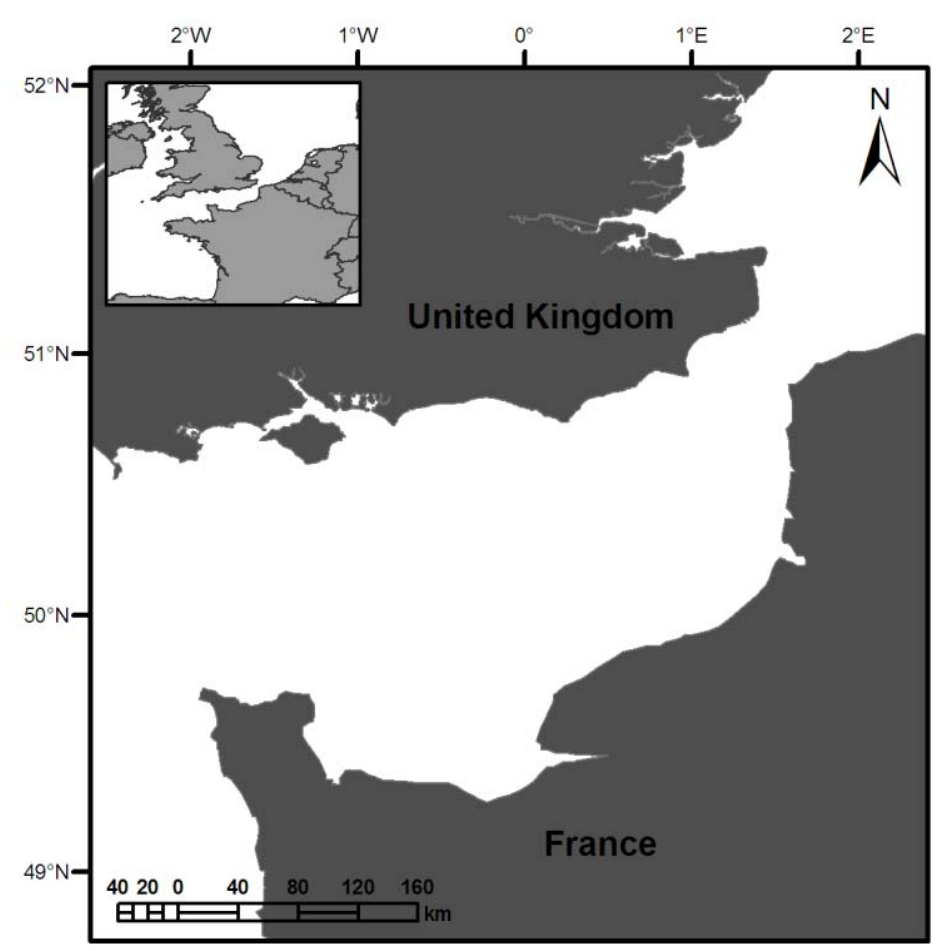


Figure 2: Seasonal typologies. Seven water masses are presented for each season.
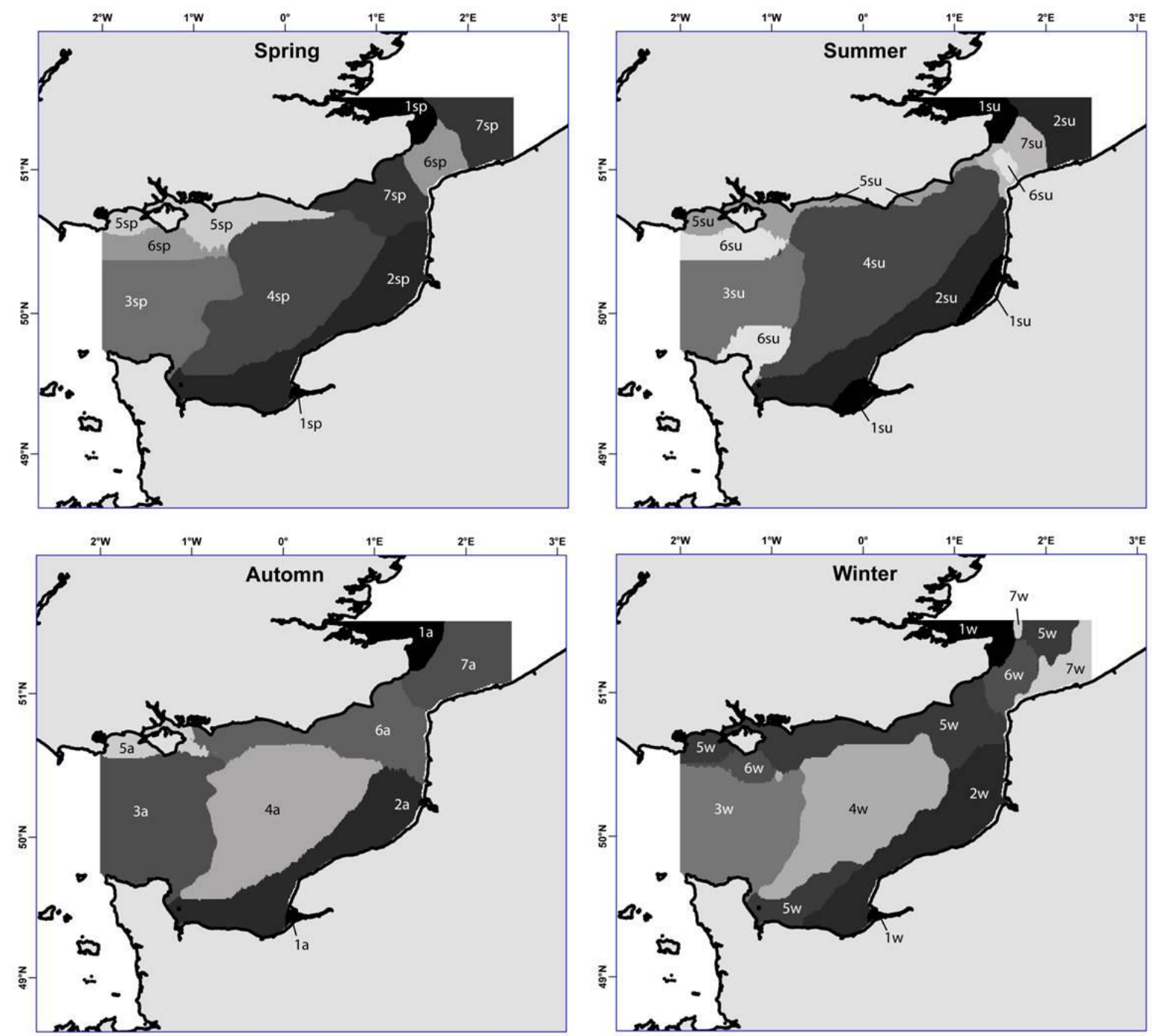
Figure 3: Variations of four parameters (Salinity, SST, depth and shear bedstress) during the four seasons in the water types 1 (sp, su, a, w), 2 (sp, su, a, w), 3 (sp, su, a, w), and 4 (sp, su, a, w).
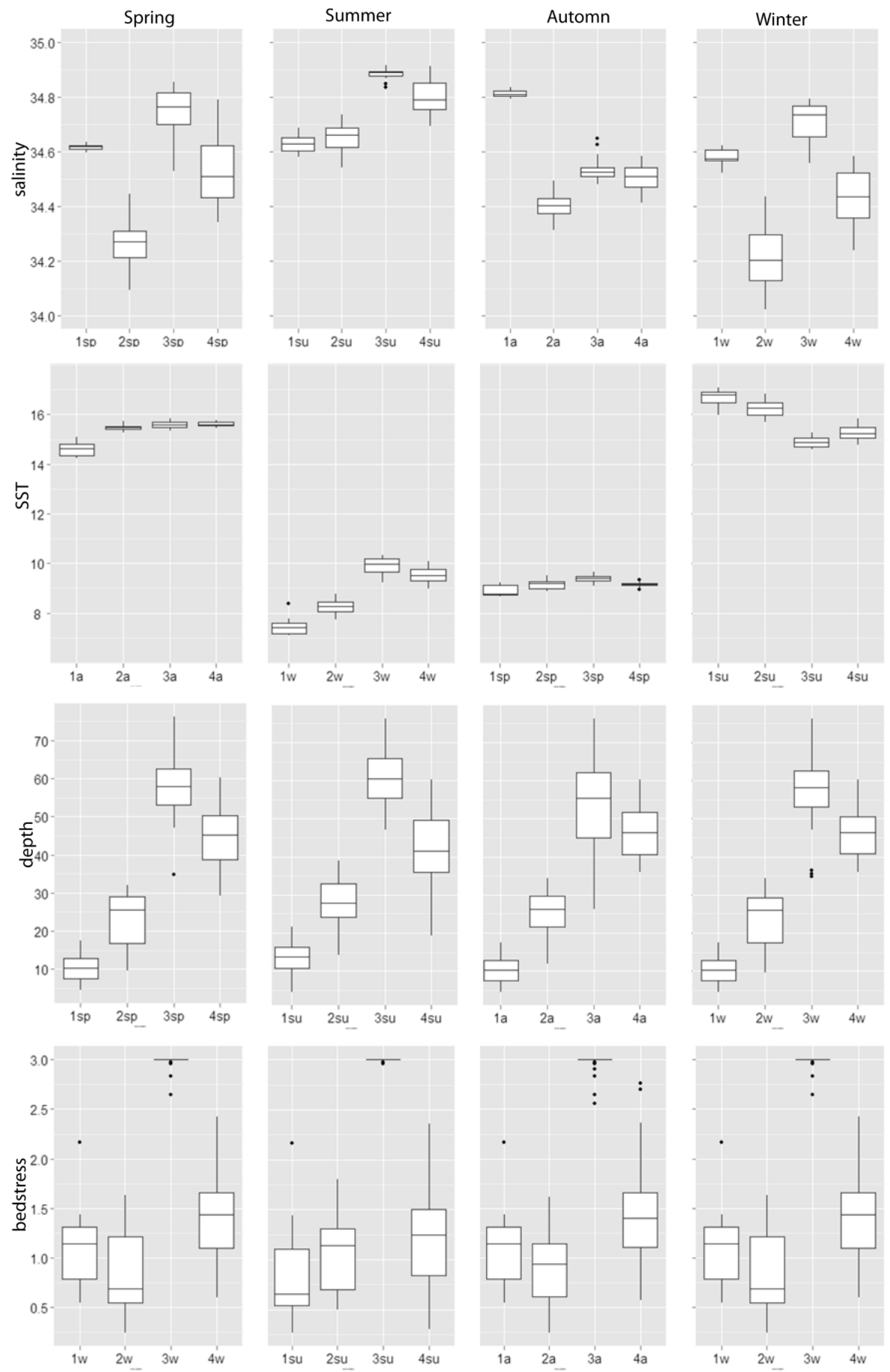
Figure 4: Multi-seasonal typology with 13 water masses presented

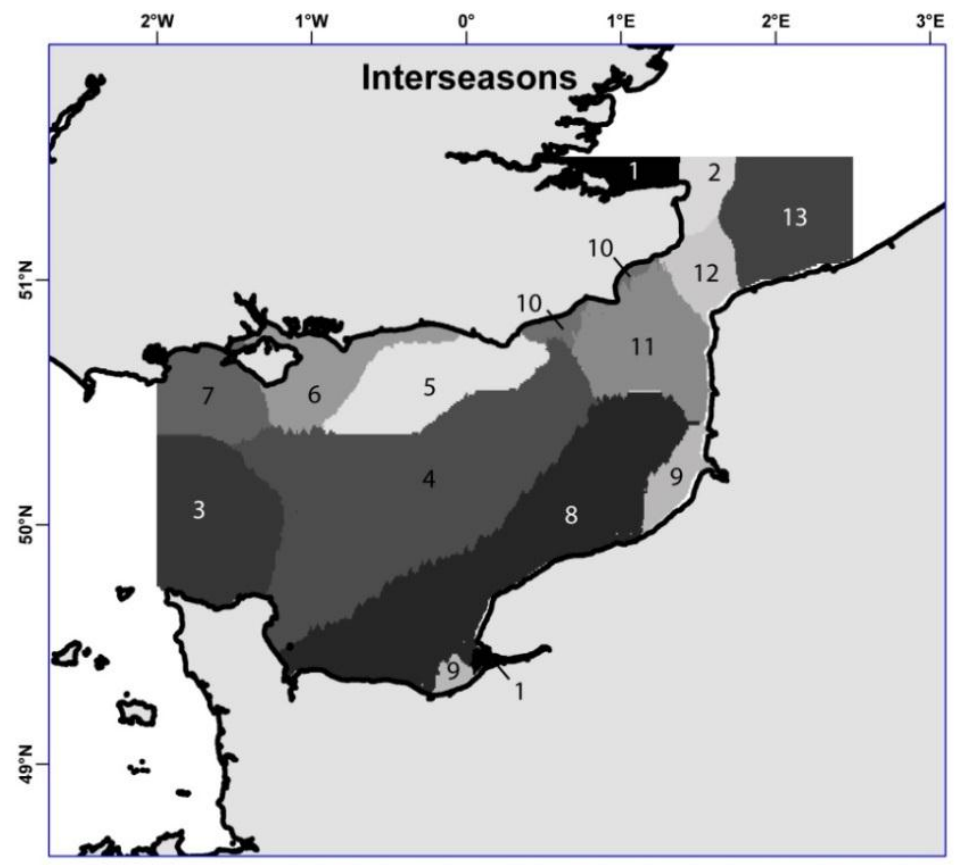


Figure 5: PCA results (two first axes) for the four seasonal typologies. a) spring, b) summer, c) autumn, d) winter. The observations plot and the variables plot are presented for each season.
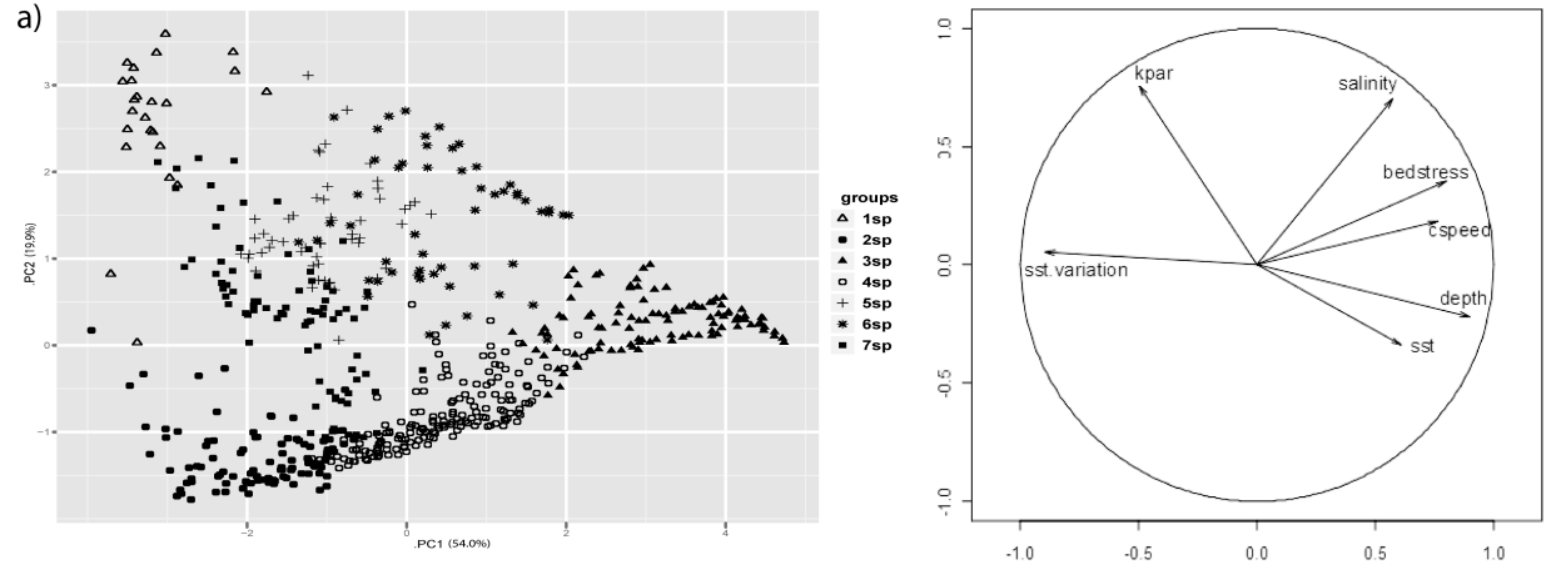

b)
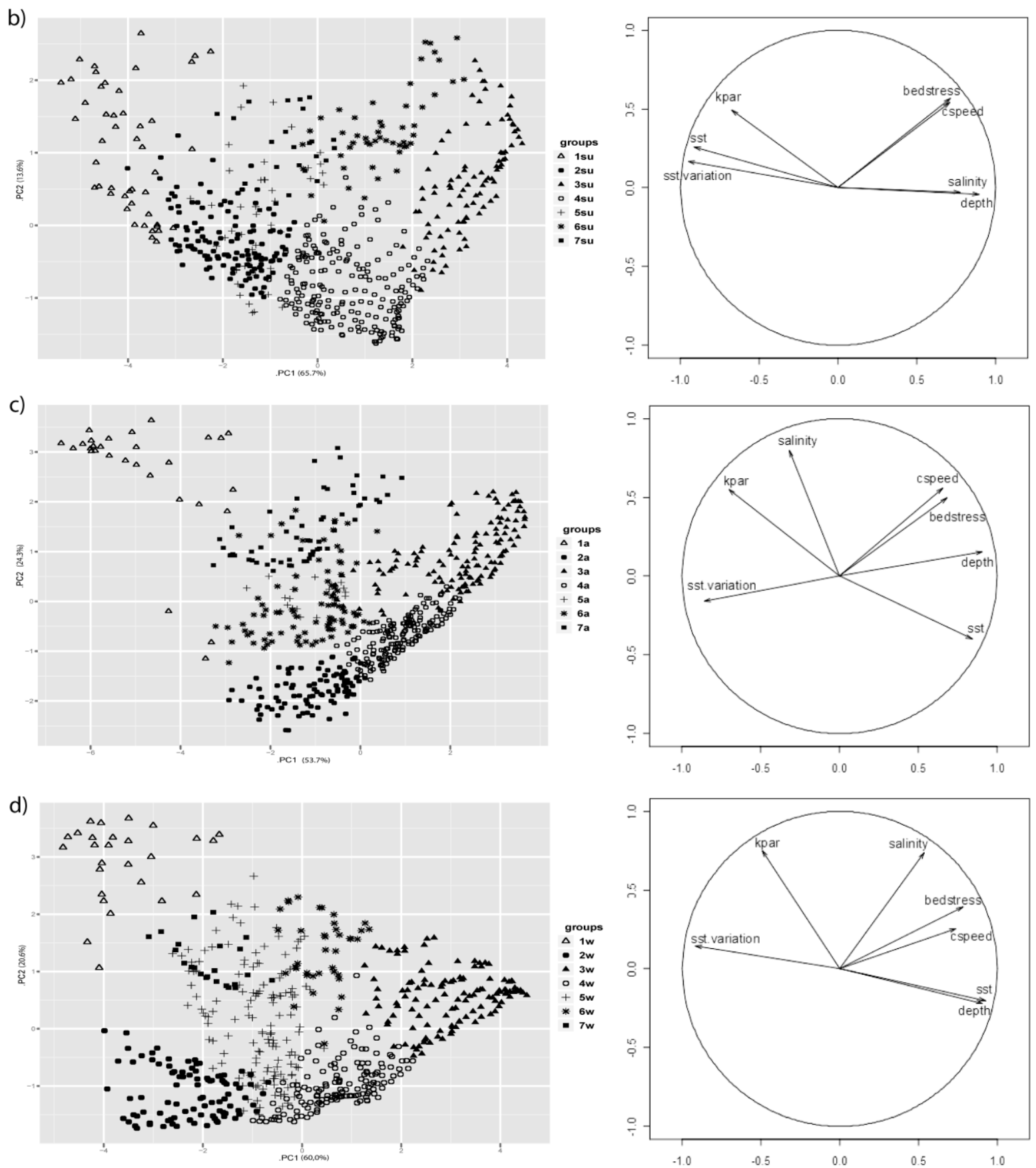